\title{
Body image quality of life in eating disorders
}

\author{
This article was published in the following Dove Press journal: \\ Patient Preference and Adherence \\ 3 March 20I I \\ Number of times this article has been viewed
}

\author{
Ignacio Jáuregui Lobera' \\ Patricia Bolaños Ríos ${ }^{2}$ \\ 'Department of Nutrition and \\ Bromatology, Pablo de Olavide \\ University, Seville, Spain; \\ ${ }^{2}$ Behavior Sciences Institute, \\ Seville, Spain
}

Correspondence: Ignacio Jáuregui Lobera Virgen del Monte 3I, Seville-4I0I I, Spain Tel +34954280789

Fax +34954278167

Email ignacio-ja@telefonica.net
Purpose: The objective was to examine how body image affects quality of life in an eating-disorder (ED) clinical sample, a non-ED clinical sample, and a nonclinical sample. We hypothesized that ED patients would show the worst body image quality of life. We also hypothesized that body image quality of life would have a stronger negative association with specific ED-related variables than with other psychological and psychopathological variables, mainly among ED patients. On the basis of previous studies, the influence of gender on the results was explored, too.

Patients and methods: The final sample comprised 70 ED patients (mean age $22.65 \pm 7.76$ years; 59 women and $11 \mathrm{men}$ ); 106 were patients with other psychiatric disorders (mean age 28.20 \pm 6.52; 67 women and 39 men), and 135 were university students (mean age $21.57 \pm 2.58$; 81 women and 54 men), with no psychiatric history. After having obtained informed consent, the following questionnaires were administered: Body Image Quality of Life Inventory-Spanish version (BIQLI-SP), Eating Disorders Inventory-2 (EDI-2), Perceived Stress Questionnaire (PSQ), SelfEsteem Scale (SES), and Symptom Checklist-90-Revised (SCL-90-R).

Results: The ED patients' ratings on the BIQLI-SP were the lowest and negatively scored (BIQLI-SP means: $+20.18,+5.14$, and -6.18 , in the student group, the non-ED patient group, and the ED group, respectively). The effect of body image on quality of life was more negative in the ED group in all items of the BIQLI-SP. Body image quality of life was negatively associated with specific ED-related variables, more than with other psychological and psychopathological variables, but not especially among ED patients.

Conclusion: Body image quality of life was affected not only by specific pathologies related to body image disturbances, but also by other psychopathological syndromes. Nevertheless, the greatest effect was related to ED, and seemed to be more negative among men. This finding is the opposite of that found in other groups studied previously.

Keywords: body image, quality of life, eating disorders, self-esteem, social functioning, gender differences

\section{Introduction}

Body image refers to individuals' attitudes toward their body, especially its appearance, which can significantly affect psychosocial functioning. ${ }^{1,2}$ As well as the investment dimension of body image attitudes (cognitive, behavioral, and emotional importance of appearance, and the sense of self), there is an evaluative component of body image including body image affective experiences in everyday life. ${ }^{1}$ Quality of life involves physical, psychological, social, and environmental aspects of a person's life. The psychological aspects of quality of life were recently included in the World Health Organization definition..$^{3-5}$ 
Because an extremely negative body image can impair psychosocial well-being and quality of life, and eating disorders (EDs) are among the most maladaptive manifestations of body image dysfunction, the treatment of body image disturbances needs to be considered as a relevant part of the clinical interventions in EDs. ${ }^{6}$ Individuals with EDs usually display significant impairments in physical, psychological, and social functioning, and several studies have shown impairment in quality of life among ED patients, highlighting the negative effect of the EDs on patient quality of life. ${ }^{7,8}$ Patients suffering from bulimia nervosa or binge ED are usually impaired in measures of quality of life and show significant impairment in psychosocial functioning. In the same way, purging behaviors and bulimic pathology seem to predict impairment in quality of life. ${ }^{9-11}$ Moreover, some researchers have found a relationship between greater severity of ED symptoms and lower quality of life..$^{12,13}$

The increased prevalence of a negative body image, especially among women, has led researchers to analyze how such dissatisfaction may vary in the degree and characteristics of its effect on an individual's quality of life. The main difficulty measuring the body image construct has been to consider it as a stable trait rather than as a variable state. Therefore it seems relevant to quantify the effects of body image on various personal experiences and life contexts. Accordingly, a new trend is based on the consideration of body image in relation to quality of life for a broad range of health conditions and disciplines, such as dermatology, oncology, endocrinology, or gynecology, among others. ${ }^{14}$ In some cases (people with EDs), the body image dissatisfaction may severely affect quality of life and have adverse psychosocial consequences, such as depression, inhibition, social anxiety, impaired sexual functioning, and poor selfesteem. $^{14}$

One of the core beliefs of EDs is related to body dissatisfaction, and other beliefs include eating and weight concerns, dieting, or binge eating. All these core beliefs are negatively associated with physical and mental health components of quality of life. ${ }^{15}$ Body dissatisfaction is the one specifically related to body image quality of life. Besides EDs, a wide range of potential psychological risk factors for body dissatisfaction has been explored (ie, anxiety, depression, and low self-esteem). It may be stated that these risk factors result in a negative self-evaluation, including a poor body image. Nevertheless, while negative effects and low self-esteem have been found to be correlated with body dissatisfaction, a causal link has not been demonstrated. ${ }^{16,17}$ In depression, the evidence suggests that rather than depression causing body dissatisfaction, body dissatisfaction may precede the development of depression. ${ }^{18,19}$

Despite body image disturbances and body image quality of life having been a focus of study on college men and women, and in different medical conditions, there is a shortage of research on the effect of body image on quality of life among ED patients, and in order to explore the specificity of that effect compared with that in other psychiatric patients. Thus, the aim of the current study was to examine how body image affects quality of life in an ED clinical sample, in a non-ED clinical sample, and in a nonclinical sample. We hypothesized that ED patients would show the worst body image quality of life. We also hypothesized that body image quality of life would be negatively associated with specific ED-related variables more than with other psychological and psychopathological variables mainly among ED patients. Finally, on the basis of previous studies (eg, Jáuregui and Bolaños ${ }^{20}$ ), the influence of gender on the results was explored.

\section{Material and methods}

\section{Participants}

The initial sample comprised 325 participants, but it was reduced to 311 after rejecting all incomplete protocols. Among the participants nobody showed any comprehension and/or language difficulties or refused to participate. The final sample comprised 70 ED patients (mean age $22.65 \pm 7.76$ years; 59 women and 11 men); 106 patients with other psychiatric disorders suffering from anxiety, depression, and adaptive disorders (mean age 28.20 \pm 6.52 ; 67 women and $39 \mathrm{men}$ ); and 135 university students, recruited from the Pablo de Olavide University and University of Seville (mean age $21.57 \pm 2.58$ years; 81 women and $54 \mathrm{men}$ ), without any psychiatric history as assessed by means of a brief questionnaire at the time of obtaining the informed consent. The various mental disorders (ED and non-ED) fulfilled the diagnostic criteria of DSMIV-TR (2000). All outpatients were receiving treatment in the Behavior Sciences Institute of Seville, and its Eating Disorders Unit. The sample of the ED patients comprised all patients who at the time of the study had recovered a normal weight and had no relevant associated psychopathology. Non-ED patients were diagnosed by means of a structured interview according to DSM-IV-TR (2000) criteria on 2 occasions: they were initially assessed by a clinical psychologist, and then, subsequently, interviewed by a psychiatrist. Only those cases with diagnostic agreement were accepted. In the case of the students, the current 
presence of a history of ED and other mental disorders was ruled out. Written informed consent was obtained from all participants.

\section{Measures}

\section{The Spanish version of Body Image} Quality of Life Inventory (BIQLI-SP) ${ }^{20}$

The BIQLI is a self-reported questionnaire, which comprises 19 items. In order to avoid pathology-oriented biases, those items are evaluated on a 7-point bipolar scale, from +3 (very positive effect) to 0 (no impact) to -3 (very negative effect). The BIQLI-SP was used for the current study. BIQLI-SP has shown high internal consistency (Cronbach's $\alpha$ coefficient $=0.95$ ) and high stability over a 3-week period (test-retest reliability $=0.84)$. The validity of the BIQLI-SP has been evidenced by its significant relationships with different variables, both psychological and psychopathological, as well as with ED-related variables.

\section{Eating Disorders Inventory-2 (EDI-2) ${ }^{21}$}

For this study the 7-item Drive for Thinness (DT) subscale, 7-item Bulimia (B) subscale, and 9-item Body Dissatisfaction (BD) subscale were administered. The BD subscale measures dissatisfaction with the overall shape and size of those parts of the body mostly related to EDs. The B subscale was designed to assess the tendency to think about and to engage in overeating episodes. The DT subscale measures excessive concern with dieting, preoccupation with weight, and fear of weight gain. The DT subscale has been used as a screening test for EDs. The internal consistency of the test, and its subscales, ranges between 0.83 and 0.92 in patient samples, and between 0.65 and 0.93 in various nonclinical samples. Test-retest reliability ranges between 0.41 and 0.97 depending on the sample. Internal consistency of the $\mathrm{BD}, \mathrm{B}$, and DT subscales in this study was $>0.80$ for men and women.

\section{Perceived Stress Questionnaire (PSQ)}

This questionnaire was designed to measure stress, and consists of 30 items that differentially measure the general (PSQ-G) and recent (PSQ-R) forms of perceived stress. The Spanish version of the $\mathrm{PSQ}^{22}$ was used in this work, and has shown excellent psychometric properties (internal consistency was 0.90 for the PSQ-G and 0.87 for the PSQ-R). The questionnaire has been used in research, demonstrating good predictive value in stress-related diseases. Internal consistency in the current study was $>0.73$ for men and women.

\section{Self-Esteem Scale (SES)}

The scale comprises 10 items that are scored using a Likert format (from strongly agree to strongly disagree): the higher the score, the higher the degree of self-esteem. The Spanish version of the instrument shows adequate internal consistency (Cronbach's $\alpha$ coefficient $=0.87)$, test-retest reliability $(r=0.72)$, and construct validity. Once again, the Spanish version was used. ${ }^{23}$ In this study the internal consistency was 0.87 for men and 0.83 for women.

\section{Symptom Checklist-90-Revised (SCL-90-R)}

This 90 -item self-report instrument measures 9 dimensions of psychological symptoms and yields 3 global indexes of distress. The measured dimensions are somatization, obsessive-compulsive, interpersonal sensitivity, depression, phobic anxiety, hostility, paranoid ideation, and psychoticism. The ninth subscale refers to miscellaneous symptoms whose low factor loading prevents their being included in the other subscales. The SCL-90-R also yields 3 global indexes of distress that measure the severity of general psychopathology: a) the GSI or Global Severity Index, which measures the degree of general distress; b) PST or Positive Symptom Total, which refers to the number of symptoms reported by the subject; and c) the PSDI or Positive Symptom Distress Index, which measures the intensity of symptoms and relates general distress with the number of symptoms. The value of Cronbach's $\alpha$ coefficient ranges from 0.81 to 0.90 , and the instrument shows adequate concurrent and predictive validity. The Spanish version of the SCL-90-R was applied to this study. ${ }^{24}$ The internal consistency in the current study ranged between 0.76 and 0.86 for both genders.

\section{Procedure}

After having obtained informed consent from all participants the above mentioned questionnaires were administered to the patients in the clinical groups. This was done in individual sessions with no time limit and in the adequate therapeutic context (ie, space in the room, light, noise). Each patient's therapist was present at the beginning of the session and explained how to complete the questionnaire. Having ensured that the instructions had been understood, the therapist then left the room so as not to be present while the patient completed the measures. The therapist then returned at the end of the session. Participation was completely voluntary in both the clinical (ED and non-ED) and control (student) groups, and none of the participants received any form of recompense. In the student group the questionnaires were 
administered by means of in-group sessions, and it was up to each individual to decide whether or not they wished their responses to remain anonymous. The study was conducted from October 2009 to September 2010.

\section{Statistical analyses}

The Kolmogorov-Smirnov test was used to determine whether the data fitted a normal distribution. When they did, a univariate analysis of variance was performed (ANOVA). In the rest of the cases, comparisons were analyzed by means of the nonparametric Kruskal-Wallis test. Nonparametric Spearman correlation coefficients (Rho) were calculated in order to analyze the association among the different psychological and psychopathological variables taken into account in this study. For the study of group differences we considered the proportion of students, non-ED patients, and ED patients with positive and negative impact of body image. In this case the analysis was developed by means of $\chi^{2}$. All these analyses were performed by means of SPSS v.16.

\section{Results}

\section{Eating disorder-related variables (EDI-2) in the different groups}

Significant differences were found in the DT subscale, with mean ranks of $191.25,182.55$, and 205.51 in the student group, non-ED patient group, and ED group, respectively $(H=8.82 ; P<0.05)$. The difference between the student group and the non-ED patient group was not significant. In the B subscale, significant differences were found; mean ranks were $144.31,145.76$, and 267.71 in the student group, non-ED patient group, and ED group, respectively ( $H=114.67 ; P<0.001)$. Once again there were no significant differences between the student group and the non-ED patient group. In the BD subscale, significant differences were found: mean ranks were $180.59,148.91$, and 241.15 in the student group, non-ED patient group, and ED group respectively $(H=52.45 ; P<0.001)$. In this case, the Kruskal-Wallis test indicated that besides the differences between the ED group and the other two groups, the difference between the SG and the non-ED patient group was significant, too.

\section{Body image quality of life in the different groups}

The total score of the BIQLI-SP fitted a normal distribution, and a univariate ANOVA was performed. Because previous studies had shown a poorer body image quality of life in women, groups and gender were entered as independent variables. The means of the total scores of the BIQLI-SP were 20.18 (15.72-24.63), 5.14 (2.25-8.02), and -6.18 $(-15.08-2.71)$ in the student group, non-ED patient group, and ED group, respectively, with a significant main effect of the group $\left(F_{2,305}=21.18 ; P<0.001\right)$. There were no significant main effects considering neither the gender $\left(F_{1,305}=1.84 ; P=0.18\right)$ nor the interaction between group and gender $\left(F_{2,305}=0.78 ; P=0.46\right)$. Despite the absence of significance for gender differences in the BIQLI-SP, it was found that only in the ED-group was body image quality of life lower in men than in women (Figure 1). Table 1 shows the positive and negative effects of body image on quality of life of the three different groups of participants. In all items of the BIQLI-SP the effect of body image on quality of life was more negative in the ED group. The analysis of the items showed that only in items 7 (My relationships with friends) and 8 (My relationships with family members) was the effect of body image positive in the ED group, while it was negative in the rest of the items. In the student group the scores of all the items were positive. Finally, in the non-ED patient group 11 items had a positive score.

\section{Association between BIQLI-SP and the different psychological and psychopathological variables}

The association was studied in each group. For the ED-related variables of the EDI-2, a significant and negative correlation between BIQLI-SP and DT $(R h o=-0.34 ; P<0.001)$ was found in the student group. In the non-ED patient group, significant and negative correlations between BIQLI-SP and DT, and B and BD subscales $(R h o=-0.40,-0.48$, and -0.47 respectively; $P<0.001)$ were found. Finally,

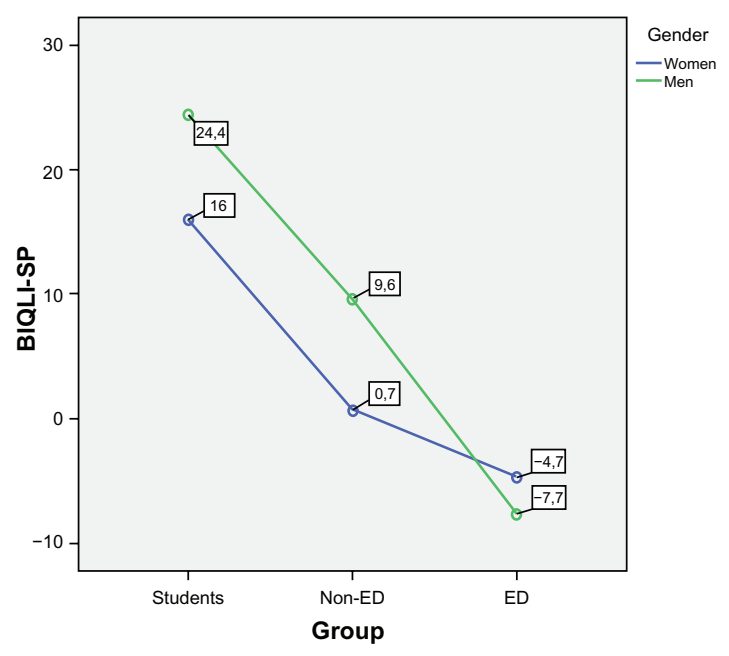

Figure I Gender differences in Body Image Quality of Life Inventory-Spanish version (BIQLI-SP) scores among the three groups.

Abbreviation: ED, eating disorder. 
Table I Reports of negative and positive effects (\%) on the Body Image Quality of Life Inventory-Spanish version (BIQLI-SP)

\begin{tabular}{|c|c|c|c|c|c|c|}
\hline \multirow[t]{2}{*}{ BIQLI-SP items } & \multicolumn{3}{|c|}{$\begin{array}{l}\text { Percentage reporting any } \\
\text { negative effect }\end{array}$} & \multicolumn{3}{|c|}{$\begin{array}{l}\text { Percentage reporting any } \\
\text { positive effect }\end{array}$} \\
\hline & SG & NEDG & EDG & SG & NEDG & EDG \\
\hline $\begin{array}{l}\text { My basic feelings about myself (feelings of } \\
\text { personal adequacy and self-worth) }\end{array}$ & 17.6 & 36.4 & 61.7 & 38.5 & 39.3 & $23.4 * * *$ \\
\hline $\begin{array}{l}\text { My feelings about my adequacy as a man or } \\
\text { woman (feelings of masculinity or femininity) }\end{array}$ & 9.9 & 20.8 & 36.2 & 74.7 & 49.5 & $38.3 * *$ \\
\hline My interactions with people of my own sex & 12.1 & 16.4 & 34.0 & 60.4 & 47.7 & $33.9 *$ \\
\hline My interactions with people of the other sex & 15.4 & 19.8 & 43.5 & 73.6 & 56.1 & $34.8 * *$ \\
\hline My experiences when I meet new people & 18.7 & 17.6 & 37.0 & 53.8 & 50.5 & $37.0^{*}$ \\
\hline My experiences at work or at school & 9.9 & 24.1 & 36.2 & 67.0 & 47.6 & $27.7 * *$ \\
\hline My relationships with friends & 4.4 & 12.3 & 28.3 & 51.1 & 53.8 & $37.0 * *$ \\
\hline My relationships with family members & 6.6 & 13.1 & 34.0 & 57.1 & 51.2 & $29.8 * *$ \\
\hline My day-to-day emotions & 14.4 & 39.9 & 46.8 & 61.1 & 31.0 & $27.7 * * *$ \\
\hline My satisfaction with my life in general & 12.1 & 45.1 & 59.6 & 71.4 & 33.8 & $29.8 * * *$ \\
\hline My feelings of acceptability as a sexual partner & 18.9 & 26.5 & 53.2 & 74.4 & 47.9 & $25.5^{* * *}$ \\
\hline My enjoyment of my sex life & 16.9 & 26.7 & 42.6 & 70.8 & 42.9 & $21.3 * * *$ \\
\hline My ability to control what and how much I eat & 16.7 & 28.9 & 55.3 & 57.8 & 34.8 & $27.7 * * *$ \\
\hline My ability to control my weight & 28.6 & 33.2 & 51.1 & 49.5 & 29.8 & $23.4 * *$ \\
\hline My activities for physical exercise & 18.9 & 30.0 & 40.4 & 61.1 & 30.0 & $27.7 * * *$ \\
\hline $\begin{array}{l}\text { My willingness to do things that might call } \\
\text { attention to my appearance }\end{array}$ & 15.7 & 26.7 & 38.3 & 47.2 & 25.7 & $27.7^{* *}$ \\
\hline $\begin{array}{l}\text { My daily "grooming" activities (ie, getting } \\
\text { dressed and physically ready for the day) }\end{array}$ & 8.9 & 29.4 & 38.3 & 60.0 & 38.9 & $38.3^{* *}$ \\
\hline How confident I feel in my everyday life & 11.0 & 39.9 & 53.2 & 71.4 & 39.9 & $36.2 * * *$ \\
\hline How happy I feel in my everyday life & 6.6 & 39.7 & 40.4 & 79.1 & 32.1 & $42.6 * * *$ \\
\hline
\end{tabular}

Notes: Percentages are based on those responding with negative $(-3,-2$, or -1$)$ or positive ratings $(+1,+2$, or +3$)$. $* P<0.05$; $* * P<0.01$; $* * * P<0.001$.

Abbreviations: SG, student group; NEDG, non-eating disorders group; EDG: eating disorders group.

in the ED-group, once again the correlations were significant and negative ( $R h o=-0.53,-0.38$, and -0.39 for DT, $\mathrm{B}$, and $\mathrm{BD}$, respectively; $P<0.001$ ).

For the rest of variables, no other significant correlations were found in the student group. In the non-ED patient group the correlation between BIQLI-SP and PSQ-G was negative ( $R h o=-0.36 ; P<0.001)$ as well as the correlations between BIQLI-SP and PSQ-R $(R h o=-0.43 ; P<0.001)$, interpersonal sensitivity (Rho $=-0.28 ; P<0.01)$, hostility (Rho $=-0.14 ; P<0.05)$, GSI (Rho $=-0.34 ; P<0.001)$, and PST $(R h o=-0.33 ; P<0.001)$. The only significant and positive correlation found was between BIQLI-SP and selfesteem ( $R h o=0.44 ; P<0.001)$. In the ED-group, no negative correlations between BIQLI-SP and the rest of variables were found. The correlation between BIQLI-SP and self-esteem was significant and positive $(R h o=0.56 ; P<0.001)$. All the correlations are shown in Tables 2 and 3.

\section{Association between BIQLI-SP and the ED-related variables after controlling for the rest of variables}

The correlation between BIQLI-SP and DT remained significant but decreased $(R h o=-0.0 .28 ; P<0.05)$ when partitioning the effects of the rest of the non-ED variables in the student group. In the non-ED patient group, the correlations between BIQLI-SP and DT, B, and BD remained significant, but decreased after controlling for the rest of variables $($ Rho $=-0.27 ; P<0.05$, Rho $=-0.33 ; P<0.01$, and Rho $=-0.30 ; P<0.01$, respectively). Finally, the correlation between BIQLI-SP and ED-related variables of the EDI-2 remained significant, after controlling for the

Table 2 Correlations between Body Image Quality of Life Inventory-Spanish version (BIQLI-SP) and the eating disorder (ED) -related variables before and after controlling for the rest of variables

\begin{tabular}{llll}
\hline & BIQLI-SP & & \\
\cline { 2 - 4 } & $\begin{array}{l}\text { Non-clinical } \\
\text { group }\end{array}$ & $\begin{array}{l}\text { Non-ED } \\
\text { group }\end{array}$ & $\begin{array}{l}\text { ED } \\
\text { group }\end{array}$ \\
\hline Biserial correlation & & & \\
$\quad$ Drive for thinness & $-0.34^{\mathrm{a}}$ & $-0.40^{\mathrm{a}}$ & $-0.53^{\mathrm{a}}$ \\
Bulimia & -0.09 & $-0.48^{\mathrm{a}}$ & $-0.38^{\mathrm{a}}$ \\
$\quad$ Body dissatisfaction & -0.08 & $-0.47^{\mathrm{a}}$ & $-0.39^{\mathrm{a}}$ \\
Partial correlation & & & \\
$\quad$ Drive for thinness & $-0.28^{\mathrm{c}}$ & $-0.27^{\mathrm{c}}$ & $-0.43^{\mathrm{a}}$ \\
Bulimia & -0.11 & $-0.33^{\mathrm{b}}$ & $-0.35^{\mathrm{a}}$ \\
Body dissatisfaction & -0.06 & $-0.30^{\mathrm{b}}$ & $-0.36^{\mathrm{a}}$ \\
\hline
\end{tabular}

Notes: ${ }^{\mathrm{p} P}<0.001$; ${ }^{\mathrm{b} P}<0.01$; $\mathrm{c} P<0.05$. 
Table 3 Correlations between Body Image Quality of Life Inventory-Spanish version (BIQLI-SP) and the psychological and psychopathological variables

\begin{tabular}{llll}
\hline & BIQLI-SP & & \\
\cline { 2 - 4 } & $\begin{array}{l}\text { Non-clinical } \\
\text { group }\end{array}$ & $\begin{array}{l}\text { Non-ED } \\
\text { group }\end{array}$ & $\begin{array}{l}\text { ED } \\
\text { group }\end{array}$ \\
\hline PSQ & & & \\
PSQ-general & -0.16 & $-0.36^{\mathrm{a}}$ & -0.12 \\
PSQ-recent & -0.17 & $-0.43^{\mathrm{a}}$ & -0.09 \\
Self-Esteem Scale & 0.11 & $0.44^{\mathrm{a}}$ & $0.56^{\mathrm{a}}$ \\
SCL-90-R & & & \\
Somatization & -0.07 & -0.10 & -0.05 \\
Obsessive-compulsive & -0.05 & -0.02 & -0.11 \\
Interpersonal sensitivity & -0.05 & $-0.28^{\mathrm{b}}$ & -0.05 \\
Depression & -0.03 & -0.04 & -0.10 \\
Phobic anxiety & -0.01 & -0.07 & -0.10 \\
Hostility & -0.06 & $-0.14^{\mathrm{c}}$ & -0.09 \\
Paranoid ideation & -0.04 & -0.02 & -0.08 \\
Psychoticism & -0.05 & -0.04 & -0.02 \\
Global severity index & -0.07 & $-0.34^{\mathrm{a}}$ & -0.10 \\
Positive symptom total & -0.04 & $-0.33^{\mathrm{a}}$ & -0.06 \\
Positive symptom & -0.01 & -0.01 & -0.10 \\
distress index & & & \\
\hline
\end{tabular}

Notes: ${ }^{p}<<0.001$; ${ }^{b P}<0.01$; ${ }^{c p}<0.05$.

Abbreviations: ED, eating disorder; PSQ, Perceived Stress Questionnaire; SCL-90-R, Symptom Checklist-90-Revised.

rest of variables $(R h o=-0.43,-0.35$, and -0.36 for DT, B and BD respectively; $P<0.001)$, in the ED-group. All the correlations are shown in Table 2.

\section{Discussion}

Body image comprises 2 aspects, both associated with psychosocial functioning. One of these aspects is the evaluation (ie, body satisfaction), and the other is the investment (in one's appearance and internalized appearance standards). As a multidimensional construct, body image comprises self-perceptions and attitudes related to one's own body. Body image attitudes are associated with self-esteem, eating behavior, sexual behavior, emotional stability, and social functioning. In many cases, as in EDs, body image dissatisfaction affects the patients' quality of life, causing severe psychosocial consequences. ${ }^{1,2,25-27}$

This study confirmed the first hypothesis, that ED patients showed the worst body image quality of life. Moreover, in all items of the BIQLI-SP the effect of body image on quality of life was more negative in the ED group. Taking into account that BIQLI-SP measures the effect of body image in different areas of psychosocial functioning (ie, interaction with people, experiences at work or at school, relationships with friends, sex life, physical exercise), that finding was consistent with the results of previous studies..$^{7-9,11}$
The second hypothesis was partially confirmed, showing that body image quality of life was negatively associated with specific ED-related variables more than with other psychological and psychopathological variables, but not especially among ED patients. The highest association between BIQLI-SP and DT subscale of the EDI-2 was found in the ED group of patients (Rho $=-0.53)$, but the association between BD and BIQLI-SP was higher in the non-ED group of patients. The association between BIQLI-SP and B subscale of the EDI-2 was similar in the ED-group and in the non-ED group. Finally, the only ED-related variable associated with BIQLI-SP in the student group was DT. Body dissatisfaction is one core belief of the ED beside others such as eating and weight concerns, dieting, purging, and binging, all of which are associated with quality of life, ${ }^{15}$ and hence with body image quality of life. These associations may be considered as a confirmation of previous reports, in which BIQLI has shown correlation with eating attitudes. ${ }^{28}$

For other psychological and psychopathological variables, the ED patient group showed a unique significant correlation, which was the positive association between BIQLI-SP and self-esteem. This result confirmed other similar findings. ${ }^{20,28}$ This association was also found in the non-ED patient group but it was lower than in the ED-group. On the other hand, different negative correlations between BIQLI-SP and other variables (PSQ-G, PSQ-R, interpersonal sensitivity, hostility, GSI, and PST) were found in the non-ED patient group. This result seems to indicate that in mental disorders other than ED, there are different variables, which could influence body image quality of life, while among ED patients body image quality of life seems to be more closely related to ED-related variables and self-esteem. In fact, in other samples comprising students, BIQLI has shown a high association, not only with eating attitudes but also with other variables such as social support or optimism. ${ }^{28}$

In addition, on the basis of previous studies ${ }^{20}$ the current study explored the influence of gender on the results. A main effect of gender on the BIQLI-SP was not found, but body image quality of life in women was worse than in men. Similar results have been found previously. ${ }^{14,20}$ Despite the absence of a main effect of gender on the BIQLI-SP, Figure 1 gives evidence that body image quality of life decreased in patients suffering from different mental disorders, maintaining a worse body image quality of life in women than in men. Moreover, Figure 1 shows that the effect of body image on quality of life was positive in women and men in the student group as well as in the non-ED group. Nevertheless, although the difference was not significant, in the ED patient group, men showed a 
worse body image quality of life than did women, and the effect was negative in both men and women. Because previous research on this field of study has usually reported a worse body image among women, this was an apparently surprising result. ${ }^{29-31}$ However, more recent studies suggest that boys experience higher levels of body dissatisfaction than girls. ${ }^{32}$ It has been suggested that late-maturing boys are more likely to experience higher levels of body dissatisfaction, ${ }^{33}$ but that could be an explanation only for the ED-group in the current study. It is widely accepted that body dissatisfaction and other weight and shape concerns have become more prevalent among adolescent boys and adult males in recent years, ${ }^{34}$ and the overall examination of the risk factors associated with disordered eating symptoms has revealed many similarities and few differences from those found in females. Moreover, body image has become more central in contemporary male culture than in previous decades. ${ }^{35}$ Thus, from this point of view the result of the current study did not constitute such a surprise finding. As some authors have pointed out, ${ }^{36}$ males and females could have different ideal body models, with certain contradictions in males who, although they are susceptible to messages about thinness, seem to pursue a more muscular body. At all events, recent studies have also shown a general rise in risk behaviors associated with EDs among males. ${ }^{37}$

The present study has some limitations. The nonclinical sample comprised only university students, and the BIQLI-SP should be applied to more diverse nonclinical community samples in future studies. Because ED patients included only 11 men, the study's ability to show gender differences could have been limited, and a more representative sample of men should be included in future studies. In the non-ED clinical sample, which comprised only patients with anxiety, depression, and adaptive disorders, it would have been interesting to include other pathologies such as body dismorphic disorder. Numerous medical conditions and treatments have been shown to negatively affect body image functioning and associated psychological consequences, ${ }^{28}$ and therefore future research could be focused on populations with such conditions and treatments.

\section{Conclusion}

Body image quality of life seems to affect not only patients with specific pathologies related to body image disturbances, but also in those with other psychopathological syndromes. Nonetheless the greatest negative effect was observed in patients with EDs, particularly in men. This finding is the opposite of that found in other groups studied previously.

\section{Acknowledgments}

We hereby state that it is an original publication, and the manuscript has not been previously submitted or published elsewhere. IJL carried out the literature research and wrote the manuscript, PBR provided critical input and corrections for the outline and writing of the manuscript. Both authors read and approved the final manuscript.

We acknowledge the support of the EDUBSI (Eating Disorders Unit of the Behavior Sciences Institute), which supported the preparation of this manuscript. Especially, thanks to Sabine Bergmann for her technical support.

\section{Disclosure}

The authors state that there are no conflicts of interest. This research received no specific grant from any funding agency in the public, commercial or non-profit sectors.

\section{References}

1. Cash TF. Cognitive-behavioural perspectives on body image. In: Cash TF, Pruzinsky T, editors. Body Image: A Handbook of Theory, Research, and Clinical Practice. New York, NY: Guilford Press; 2002:38-46.

2. Cash TF, Pruzinsky T, editors. Body Image: A Handbook of Theory, Research, and Clinical Practice. New York, NY: Guilford Press; 2002.

3. Chopra PK, Couper JW, Herrman H. The assessment of disability in patients with psychotic disorders: An application of the ICIDH-2. Aust N Z J Psychiatry. 2002;36:127-132.

4. Chopra PK, Couper JW, Herrman H. The assessment of patients with long-term psychotic disorders: Application of the WHO disability assessment schedule II. Aust N Z J Psychiatry. 2004;38:753-759.

5. WHOQOL Group. Development of the World Health Organisation WHOQOL-BREF quality of life assessment. Psychol Med. 1998;28: $551-558$.

6. Cash TF, Hrabosky JI. Treatment of body image disturbances. In: Thompson JK, editor. Handbook of Eating Disorders and Obesity. Oboken, NJ: John Wiley \& Sons. Inc; 2004:515-541.

7. de la Rie SM, Noordenbos G, van Furth EF. Quality of life and eating disorders. Qual Life Res. 2005;14:1511-1522.

8. Doll HA, Petersen SE, Stewart-Brown SL. Eating disorders and emotional and physical well-being: Associations between student self-reports of eating disorders and quality of life as measured by the SF-36. Qual Life Res. 2005;14:705-717.

9. González-Pinto A, Failde I, Rodríguez C, Fernández de Corres B, Enjuto $\mathrm{S}$, et al. Purging behaviors and comorbidity as predictive factors of quality of life in anorexia nervosa. Int J Eat Disord. 2004;36; $445-450$.

10. Hay P. Quality of life and bulimic eating disorder behaviors: Findings from a community-based sample. Int J Eat Disord. 2003;33: 434-442.

11. Padierna A, Quintana JM, Arostegui I, Gonzalez N, Horcajo MJ. The health-related quality of life in eating disorders. Qual Life Res. 2000;9:667-674.

12. Mond JM, Hay PJ. How to 'count the cost' and measure burden? A review of health-related quality of life in people with eating disorders. J Ment Health. 2005;14:539-552.

13. Mond JM, Hay PJ, Rodgers B, Owen C, Beumont PJV. Temporal stability of the eating disorder examination questionnaire. Int $J$ Eat Disord. 2004;36:195-203.

14. Cash TF, Fleming EC. The impact of body image experiences: Development of the Body Image Quality of Life Inventory. Int $J$ Eat Disord. 2002;31:455-460. 
15. Vallance JK, Latner JD, Gleaves DH. The relationship between eating disorder psychopathology and health-related quality of life within a community sample. Qual Life Res. 2010. doi 10.1007/s11136-010-9799-x.

16. Ohring R, Graber JA, Brooks-Gunn J. Girls' recurrent and concurrent body dissatisfaction: Correlates and consequences over 8 years. Int $J$ Eat Disord. 2002;31:404-415.

17. Wertheim EH, Paxton SJ, Blaney S. Risk factors for body image dissatisfaction. In: Thompson JK, editor. Handbook of Eating Disorders and Obesity. New York: Wiley; 2004:463-494.

18. Stice E, Bearman SK. Body-image and eating disturbances prospectively predict increases in depressive symptoms in adolescent girls: A growth curve analysis. Dev Psychol. 2001;37:597-607.

19. Stice E, Hayward C, Cameron RP, Killen JD, Taylor CB. Body-image and eating disturbances predict onset of depression among female adolescents: A longitudinal study. J Abnorm Psychol. 2000;109:438-444.

20. Jáuregui Lobera I, Bolaños Ríos P. Body image and quality of life in Spanish population. Int J Gen Med. 2011;4:1-10.

21. Garner DM. Inventario de Trastornos de la Conducta Alimentaria-2. Madrid, Spain: Tea Ediciones; 1998.

22. Sanz-Carrillo C, García-Campayo J, Rubio A, Santed MA, Montoro M. Validation of the Spanish version of the Perceived Stress Questionnaire. J Psychosom Res. 2002;52:167-172.

23. Vázquez AJ, Jiménez R, Vázquez-Morejón R. Escala de autoestima de Rosenberg: fiabilidad y validez en población clínica española. Apuntes de Psicología. 2004;22:247-255.

24. González de Rivera JL, Derogatis LR, de las Cuevas C, Gracia Marco R, Rodríguez-Pulido F, Henry Benítez M, et al. The Spanish Version of the SCL-90-R. Normative Data in the General Population. Towson: Clinical Psychometric Research; 1989.

25. Thompson JK, Heinberg LJ, Altabe M, Tantleff-Dunn S. Exacting Beauty: Theory, Assessment, and Treatment of Body Image Disturbance. Washington, DC: American Psychological Association; 1999.

26. Cash TF. The psychology of physical appearance: Aesthetics, attributes, and images. In: Cash TF, Pruzinsky T, editors. Body Images: Development, Deviance, and Change. New York: Guilford Press; 1990:51-79
27. Cash TF. Body image attitudes: Evaluation, investment, and affect. Percept Mot Skills. 1994;78:1168-1170.

28. Cash TF, Jakatdar TA, Fleming E. The Body Image Quality of Life Inventory: Further validation with college men and women. Body Image. 2004; 1:279-287.

29. Moore DC. Body image and eating behavior in adolescents. J Am Coll Nutr. 1993;12:505-510.

30. Nowak M, Speare R, Crawford D. Gender differences in adolescent weight and shape-related beliefs and behaviour. J Paediatr Child Health. 1996;32:148-152.

31. Rosenblum GD, Lewis M. The relations among body image, physical attractiveness, and body mass in adolescence. Child Dev. 1999;70: 50-64.

32. McCabe MP, Ricciardelli LA. Sociocultural influences on body image and body changes among adolescent boys and girls. J Soc Psychol. 2003;143:5-26.

33. Siegel JM, Yancey AK, Aneshensel CS, Schuler R. Body image, perceived pubertal timing, and adolescent mental health. J Adolesc Health. 1999;25:155-165.

34. Pope HG, Phillips K, Olivardia R. The Adonis Complex. How to Identify, Treat, and Prevent Body Obsession in Men and Boys. New York: A Touchstone Book; 2000.

35. Pope HG, Gruber AJ, Mangweth B, Bureau B, deCol C, et al. Body image perception among men in three countries. Am J Psychiatry. 2000; 157:1297-301.

36. Olesti M, Piñol JL, Martín N, de la Fuente M, Riera A, Bofarull JM, et al. Prevalence of anorexia nervosa, bulimia nervosa and other eating disorders in adolescent girls in Reus (Spain). An Pediatr (Barc). 2008; 68:18-33.

37. Jáuregui Lobera I, Romero Candau J, Bolaños Ríos P, Montes Berriatúa C, Díaz Jaramillo R, Montaña González MT, et al. Conducta alimentaria e imagen corporal en una muestra de adolescentes de Sevilla. Nutr Hosp. 2009;24:568-557.
Patient Preference and Adherence

\section{Publish your work in this journal}

Patient Preference and Adherence is an international, peer-reviewed, open access journal focusing on the growing importance of patient preference and adherence throughout the therapeutic continuum. Patient satisfaction, acceptability, quality of life, compliance, persistence and their role in developing new therapeutic modalities and compounds to

\section{Dovepress}

optimize clinical outcomes for existing disease states are major areas of interest. This journal has been accepted for indexing on PubMed Central. The manuscript management system is completely online and includes a very quick and fair peer-review system. Visit http://www.dovepress.com/ testimonials.php to read real quotes from published authors. 